\title{
A teoria da interpretação jurídica de Hans Kelsen: uma crítica a partir da obra de Friedrich Müller
}

\author{
Sérgio Urquhart Cademartori* \\ Nestor Castilho Gomes**
}

\begin{abstract}
Sumário: Introdução; 1. A Teoria Pura do Direito: a distinção entre ser e dever-ser como traço fundamental do projeto epistemológico kelseniano; 2. A teoria da interpretação jurídica de Hans Kelsen; 3. Críticas à teoria da interpretação de Kelsen a partir da obra de Friedrich Müller. Considerações finais. Referências.
\end{abstract}

Resumo: $\mathrm{O}$ artigo analisa a teoria da interpretação jurídica de Hans Kelsen, apresentada na Teoria Pura do Direito, a partir da posição teórica de Friedrich Müller, isto é, a partir das críticas formuladas pela Teoria Estruturante do Direito. Demonstrar-se-á como a distinção entre ser e dever-ser, traço fundamental do projeto epistemológico kelseniano, influenciou a teoria da interpretação por ele proposta. Outrossim, o presente trabalho expõe em detalhes a teoria da interpretação jurídica de Kelsen para, posteriormente, efetuar um inventário das críticas que lhe são formuladas, tendo como fio condutor a obra de Friedrich Müller, sem prejuízo da abordagem de outros autores.

Palavras-chave: Interpretação jurídica; Hans Kelsen; Friedrich Müller.

\begin{abstract}
The article examines the theory of legal interpretation as presented by Hans Kelsen on his "Pure Theory of Law", under the critical approach of Friedrich Müller, on his "Structuring Theory of Law" [Strukturiende Rechstslehre]. The article shall demonstrate how Kelsen's distinction between sein [being] and sollen [should be] - as a fundamental feature of his epistemological project - influenced the theory of interpretation he proposed. Also, this work presents in detail the theory of legal interpretation of Kelsen to thereafter make an inventory of critics formulated about it, under the guideline from works of Friedrich Müller, besides the approach of other authors.
\end{abstract}

Keywords: Legal interpretation; Hans Kelsen; Friedrich Müller.

\section{Introdução}

O presente artigo pretende realizar uma aproximação à teoria da interpretação jurídica de Hans Kelsen, apresentada na Teoria Pura do Direito, a partir da posição

\footnotetext{
${ }^{*}$ Doutor em Direito pela UFSC. Professor do CPGD/UFSC.

** Mestrando em Direito do CPGD/UFSC. Especialista em Direito Constitucional pela Academia Brasileira de Direito Constitucional. Advogado.
} 
teórica de Friedrich Müller - isto é, a partir das críticas formuladas pela Teoria Estruturante do Direito. Dado que as formulações kelsenianas se constituem em ponto de partida privilegiado para todas aquelas correntes que intentam superar e/ ou negar o positivismo jurídico, uma sua exposição torna-se condição de possibilidade para a compreensão das teses que se lhe contrapõem: entende-se que não haveria sentido em discorrer sobre a teoria da interpretação jurídica de Kelsen - que remete, em sua última edição, aos idos da década de 60 do século passado - a não ser sob o fio condutor de uma nova posição teórica. Assim é que a obra de Kelsen será abordada tendo em vista as críticas de Müller, em especial aquelas dirigidas à sua teoria da interpretação e à sua concepção de norma.

Para aqueles habituados à obra de Friedrich Müller, uma crítica à teoria da interpretação de Kelsen não chega a causar surpresa. Afinal, Müller decreta o colapso da Teoria Pura do Direito ao dizer que, "ali onde Kelsen pensava dever parar, ali começa o trabalho"1.

A primeira seção do presente trabalho analisará alguns aspectos da Teoria Pura do Direito, em especial o seu projeto epistemológico, assente na distinção entre ser (sein) e dever-ser (sollen), com sua conseqüente concepção de norma e de ordenamento jurídico, a influenciar decisivamente a teoria da interpretação jurídica. Tal análise se faz importante, pois, como diz Luis Alberto Warat, Kelsen não se detém na construção da ciência do direito, mas "uma vez estabelecidas as regras de seu jogo epistemológico, decide aplicá-las para ver o que acontece"2.

Após a exposição do projeto epistemológico de Kelsen, será elaborada, na segunda seção, uma exposição detalhada da teoria da interpretação jurídica proposta na Teoria Pura do Direito. Buscar-se-á descrever as principais categorias da teoria da interpretação de Kelsen, isto é: (i) as espécies de interpretação, (ii) a questão da moldura normativa e a (iii) possibilidade de criação de direito para além dos limites impostos pelo quadrante normativo.

$\mathrm{Na}$ terceira seção analisar-se-á criticamente a teoria da interpretação jurídica de Kelsen, buscando traçar linhas de contato com sua concepção de ciência, norma e ordenamento jurídico. As críticas à teoria da interpretação de Kelsen terão como fio condutor aquelas dispostas na Teoria Estruturante do Direito, de Friedrich Müller, sem prejuízo da abordagem de outros autores. Estes serão utilizados, com senso de conveniência, sempre que suas críticas estejam albergadas, de alguma forma, pela

\footnotetext{
${ }^{1}$ Müller refere-se à teoria da interpretação jurídica de Kelsen, capítulo final da Teoria Pura do Direito. MÜLLER, Friedrich. O novo paradigma do direito: introdução à teoria e metódica estruturantes do direito. São Paulo: RT, 2007. p. 248.

${ }^{2}$ WARAT, Luís Alberto; PÊPE, Albano Marcos Bastos. Filosofia do direito: uma introdução crítica. São Paulo: Moderna, 1996. p. 54.
} 
teoria de Müller. Refoge aos limites do presente trabalho a exposição da Teoria Estruturante do Direito ou mesmo da metódica estruturante. Buscar-se-á, porém, traçar algumas diferenças entre a Teoria Pura do Direito e a Teoria Estruturante do Direito, tendo em vista que a obra de Müller é construída a partir da recusa do legado do positivismo normativista.

Nas considerações finais apresentar-se-á uma síntese do modelo epistemológico e da teoria da interpretação de Kelsen, bem como um inventário das principais críticas que lhe são formuladas por Müller.

\section{A Teoria Pura do Direito: a distinção entre ser e dever-ser como traço fundamental do projeto epistemológico kelseniano}

Com a Teoria Pura do Direito, Kelsen propõe um novo paradigma epistemológico para a ciência do direito. A obra de Kelsen é uma epistemologia jurídica que pretende criticar e substituir o conhecimento jurídico-científico elaborado até então. A Teoria Pura procura responder à questão: o que é e como é o Direito? Isto não significa que Kelsen estivesse interessado no direito em si. A preocupação de Kelsen era de cariz epistemológico. O que verdadeiramente objetivava responder era: o que é a ciência do direito? Como é possível fundar a ciência do direito? ${ }^{3}$

A Teoria Pura é uma teoria do direito positivo e, nas palavras de Kelsen, uma teoria geral do direito. Ela não se importa em como o direito deve ser, mas em como ele é. Não se preocupa, pois, em explicitá-lo, transformá-lo, nem tampouco justificálo, pois deve estar depurada de toda a ideologia (postulado da neutralidade valorativa da ciência). É eminentemente ciência do direito e não política do direito ${ }^{4}$.

O seu princípio fundamental é a "pureza" metodológica. Kelsen procurou erigir uma ciência do direito sob um ponto de vista exclusivamente jurídico, isto é, fundada sob bases exclusivamente normativas. A Teoria Pura do Direito, como ciência específica do direito, restringe-se, portanto, às normas jurídicas. Cabe à ciência do direito extirpar todos os elementos que lhe são estranhos, todos os elementos classificados como metajurídicos, caso queira alcançar o ideal de toda ciência: objetivi-

\footnotetext{
${ }^{3}$ Cf. KELSEN, Hans. Teoria pura do direito. Trad. João Baptista Machado. 7. ed. São Paulo: Martins Fontes, 2006. p. 01; WARAT, Luís Alberto. Op. cit., p. 48/49.

${ }^{4}$ KELSEN, Hans. Op. cit., p. 01; WARAT, Luís Alberto. Op. cit., p. 49; TROPER, Michel. Por una teoría del Estado. Trad. Maria Venegas Grau. Madrid: Dykinson, 2001. p. 26.
} 
dade e exatidão ${ }^{5}$.A excessiva preocupação cientificista de Kelsen merece ser melhor contextualizada. No final do século XIX e começo do século XX, a autonomia da ciência jurídica estava em xeque, envolta numa luta fatricida entre positivistas empíricos de diversos matizes (positivismo jurídico sociológico de Rudolf von Jhering no seu período tardio, positivismo psicológico de Ernest Rudolf Bierling) e defensores do Direito natural ${ }^{6}$. Kelsen procurou então salvaguardar a ciência do direito, ao propor que seu método e objeto fossem exclusivamente normativos.

Como neokantiano, Kelsen empreende a fundamentação da autonomia metodológica da ciência do direito a partir da distinção entre ser e dever-ser. A diferença entre ser e dever-ser é, para Kelsen, insusceptível de maior explicação; é nos dada imediatamente à consciência. Segundo Kelsen:

Ninguém pode negar que o enunciado: tal coisa é - ou seja, o enunciado através do qual descrevemos um ser fático - se distingue essencialmente do enunciado: algo deve ser - com o qual descrevemos uma norma - e que da circunstância de algo ser não se segue que algo deva ser, assim como da circunstância de que algo deve ser se não segue que algo seja ${ }^{7}$.

Kelsen aduz que a ciência do direito não tem a ver com fatos, com a conduta efetiva dos homens (ser, sein), mas com o prescrito juridicamente (dever-ser, sollen). Kelsen propugna que a ciência do direito não pode ser uma ciência da natureza, que se preocupa com a descrição de fatos e a investigação causal. O jurista austríaco refuta, assim, o estatuto de cientificidade do positivismo empírico, que se arroga como verdadeira ciência do direito, por proceder empiricamente, do mesmo modo que as ciências da natureza ${ }^{8}$.

Outrossim, Kelsen propõe a separação entre direito e política. A ciência do direito não pode ser confundida com a jurisprudência dogmática, que procede de modo normativo (valorativo) ${ }^{9}$. A jurisprudência dogmática pertenceria ao âmbito da política do direito. Firme no postulado da neutralidade valorativa da ciência, Kelsen afirma que a ciência do direito só pode ser uma ciência das formas puras do direito, uma ciência puramente normativa.

Como nos ensina Castanheira Neves, Kelsen une elementos do neokantismo e do positivismo científico para extirpar, respectivamente, a sociologia e a política do âmbito da ciência do direito. Nas palavras do catedrático de Coimbra:

${ }^{5}$ KELSEN, Hans. Op. cit., prefácio; 1.

${ }^{6}$ KAUFMANN, Arthur. Filosofia do direito. Trad. António Ulisses Cortês. Lisboa: Calouste Gulbenkian, 2004. p. 21.

${ }^{7}$ KELSEN, Hans. Op. cit., p. 6.

${ }^{8}$ KAUFMANN, Arthur. Op. cit., p. 21.

${ }^{9}$ KAUFMANN, Arthur. Op. cit., p. 21. 
[...] o seu neokantismo de origem lhe determinou um dualismo metodológico em que o postulado de não sociologização da ciência do direito foi evidente corolário e se exprimiria numa delimitativa ou específica intencionalidade objetivante, o seu positivismo científico (o positivismo do herdado cientificismo do século XIX e epistemologicamente depurado na radicalização empírico-analítica deste século) impôs-lhe, por sua vez, e para o cumprimento estrito dessa intenção tão-só teorética, um postulado de não politização da mesma ciência do direito, que dela excluiria todos os momentos axiológico-normativamente constitutivos e os remeteria para os domínios não científicos do ideológico-político e da opção subjetiva ${ }^{10}$.

A exclusão destes elementos da ciência do direito não significa que Kelsen os desprezasse. Conforme sintetiza, e.g., o próprio jurista de Viena, "o direito não pode ser separado da política, pois é um essencial instrumento da política, mas a ciência do direito pode e deve ser separada da política"11. Efetivamente, o que Kelsen objetivava era evitar um sincretismo metodológico que afundasse a ciência do direito em discussões estéreis, alheias ao seu propalado objeto, a norma jurídica ${ }^{12}$.

Ainda no campo da relação Direito e ciência, Kelsen entende como insuficiente a distinção entre ciências naturais e ciências sociais, utilizada para fins de classificação do objeto da ciência do direito entre os dois pólos. Isto porque, para Kelsen, assim como a sociedade pode ser pensada como parte da natureza, o Direito também tem parte de seu ser inserida no domínio da natureza. A diferença fundamental entre a ciência natural e a ciência do direito reside na distinção entre nexo de causalidade e nexo de imputação.

A ciência da natureza produz a lei: "se A é, B é", numa relação de causalidade necessária. Existe uma implicação, em relação de causa e efeito, entre um fato anterior e a ocorrência do fato posterior. Se desprendermos uma maçã do alto de uma macieira, ela cairá. A queda (fato posterior) é decorrência necessária do desprendimento da maçã (fato anterior). Tal fato ocorrerá, independentemente do tempo e do local, sempre que a experiência for repetida nas mesmas condições.

Já a ciência do direito produz a lei: "se A é, B deve ser". Inexiste, na ciência do direito, uma relação de causalidade entre fatos e conseqüências. Assim, e.g., se alguém comete um determinado crime, deve ser-lhe aplicada uma sanção. Vigora, pois, o princípio da imputação, que determina que, verificada uma condição (crime), seja aplicada uma determinada conseqüência (sanção). Entretanto, se a sanção

\footnotetext{
${ }^{10}$ CASTANHEIRA NEVES, Antônio. Método jurídico. Digesta: escritos acerca do direito, do pensamento jurídico, de sua metodologia e outros. Coimbra: Coimbra, 1995. vol. II. p. 101.

${ }^{11}$ KELSEN, Hans. Was ist die Reine Rechtslehre? p. 620 apud CASTANHEIRA NEVES, Antônio. Op. cit., p. 386.

12 KELSEN, Hans. Op. cit., p. 2.
} 
(conseqüência) não for aplicada, as leis que regem a ciência do direito não são invalidadas. Se as normas jurídicas não descrevem o que é, mas o que deve ser, a ciência do direito não pode descrever ou predizer o que será, mas unicamente enunciar que, em determinadas condições definidas pelo ordenamento jurídico, devem produzir-se determinadas conseqüências ${ }^{13}$.A norma jurídica, objeto da ciência do direito, se apresenta como esquema de interpretação ${ }^{14}$ e como sentido objetivo de um dever-ser. Segundo a rigorosa conceituação de Hans Kelsen, “"norma' é o sentido de um ato através do qual uma conduta é prescrita, permitida ou, especialmente, facultada, no sentido de adjudicada à competência de alguém"15. Faz-se necessário, desde já, aclarar esta dupla dimensão da norma jurídica enquanto: (i) esquema de interpretação e (ii) sentido objetivo de dever-ser.

Enquanto esquema de interpretação, a norma serve como filtro de juridicidade aos atos que se realizam no espaço e no tempo, sensorialmente perceptíveis. Conforme assevera Kelsen, o fato recebe um sentido jurídico específico por intermédio de uma norma que a ele se refere com o seu conteúdo, que lhe empresta a significação jurídica ${ }^{16}$. Assim, por exemplo, é por intermédio de uma norma jurídica que o fato de uma morte na guilhotina se constitui como execução jurídica de uma sentença de condenação à pena capital e não como homicídio.

Por outro lado, o direito é uma ordem normativa da conduta humana, isto é, um sistema de normas que regulam o comportamento humano. A norma jurídica possui o sentido específico de um ato intencional dirigido à conduta de outrem (sentido objetivo de dever-ser). Kelsen considera a norma como técnica indireta de motivação das condutas humanas. Salienta, entretanto, que a norma não se confunde com a vontade que a produziu. A norma não é algo de psíquico real ${ }^{17}$. A norma é um dever-ser, ao passo que o ato de vontade da qual ela é o sentido objetivo, constitui um ser. Donde se conclui a estreita vinculação entre norma e ato de vontade.

\footnotetext{
${ }^{13}$ TROPER, Michel. Op. cit., p. 26.

${ }^{14}$ Nas palavras de Kelsen: "O juízo em que se enuncia que um ato de conduta humana constitui um ato jurídico (ou antijurídico) é o resultado de uma interpretação específica, a saber, de uma interpretação normativa”. Cf. KELSEN, Hans. Op. cit., p. 4.

${ }^{15}$ KELSEN, Hans. Op. cit., p. 6.

${ }^{16}$ KELSEN, Hans. Op. cit., p. 4.

${ }^{17}$ Como bem sintetiza Miguel Reale: “As normas jurídicas não são comandos ou imperativos, no sentido psicológico do termo, como se detrás de cada preceito houvesse alguém a dar ordens, mas sim enunciados lógicos que se situam no plano do dever ser". REALE, Miguel. Filosofia do direito. 11. ed. São Paulo: Saraiva, 1986. p. 457. No mesmo sentido: LARENZ, Karl. Metodologia da ciência do direito. Trad. José Lamego. 2. ed. Lisboa: Calouste Gulbenkian, 1983. p. 84; KELSEN, Hans. Op. cit., p. 6.
} 
As normas jurídicas não são fatos, mas o sentido destes, ou seja, o sentido de atos de vontade direcionados para o comportamento humano ${ }^{18}$. A validade de uma norma jurídica não resulta de seu conteúdo, mas apenas da sua criação por uma forma determinada, em última instância, por uma norma fundamental pressuposta (fonte comum de validade de todas as normas pertencentes ao sistema) ${ }^{19}$. A norma jurídica é, pois, materialmente vazia. A discussão acerca do conteúdo ou da materialidade da norma jurídica não é posta pela Teoria Pura do Direito, pois irrelevante do ponto de vista jurídico-científico. Efetivamente, para Kelsen, "todo e qualquer conteúdo pode ser direito"20.

Outra distinção importante (com repercussão na teoria da interpretação kelseniana) é aquela operada entre norma jurídica e proposição jurídica. Como se verá a seguir, a distinção entre norma jurídica e proposição jurídica corresponde à diferença entre interpretação autêntica e interpretação não-autêntica. Proposições jurídicas são juízos hipotéticos, formulados pela ciência do direito, sem interferências valorativas, que enunciam que, de acordo com o sentido de uma ordem jurídica dada ao conhecimento sob determinadas condições fixadas por este ordenamento, devem intervir certas conseqüências positivadas neste mesmo ordenamento $^{21}$.

De outro lado, normas jurídicas são mandamentos, comandos, imperativos. Enquanto a ciência do direito tem por função conhecer o direito e descrevê-lo, os órgãos jurídicos têm por missão produzir o direito para que ele possa ser conhecido e descrito pela ciência do direito. Assim, norma jurídica e proposição jurídica têm caráter logicamente diverso. A distinção revela-se no fato das proposições jurídicas formuladas pela ciência do direito poderem ser verídicas ou inverídicas (i.é., conforme a vinculatividade da descrição a uma norma jurídica válida), enquanto as normas jurídicas podem ser válidas ou inválidas (conforme provenham ou não de uma outra norma jurídica válida $)^{22}$.

\footnotetext{
${ }^{18}$ MÜLLER, Friedrich. Op. cit., p. 48.

${ }^{19}$ KELSEN, Hans. Op. cit., p. 221. Ainda sobre a questão da validade das normas jurídicas, prossegue Kelsen: "Se se pergunta pelo fundamento de validade de uma norma pertencente a uma determinada ordem jurídica, a resposta apenas pode consistir na recondução à norma fundamental desta ordem jurídica, quer dizer: na afirmação de que esta norma foi produzida de acordo com a norma fundamental". KELSEN, Hans. Op. c

it., p. 222.

${ }^{20}$ KELSEN, Hans. Op. cit., p. 221.

${ }^{21}$ KELSEN, Hans. Op. cit., p. 80.

${ }^{22}$ KELSEN, Hans. Op. cit., p. 80/84.
} 


\section{A teoria da interpretação jurídica de Hans Kelsen}

A questão acerca da importância que Kelsen atribuiu ao tema da interpretação jurídica ao longo de sua obra é bastante controversa. Enquanto alguns autores entendem que ela ocupa posição marginal no contexto da obra do jurista austríaco ${ }^{23}$, outros asseveram que ele debruçou-se suficientemente sobre o tema ${ }^{24}$. A interpretação surge na obra de Kelsen quando da publicação do artigo intitulado "Zur Theorie der Interpretation", no periódico Internationale für Theorie des Rechts, em 193425. No mesmo ano, o artigo em referência é reproduzido, sem maiores alterações, na primeira edição da Teoria Pura do Direito ${ }^{26}$. É somente na segunda edição da Teoria Pura, publicada em 1960, que o tema da interpretação será ostensivamente abordado, ainda que em uma dezena de páginas.

A originalidade de Kelsen no campo metodológico decorre sobretudo da defesa de uma opção voluntarista, e não cognitiva, do ato de realização do direito, e no rechaço da antinomia tradicional entre criação e aplicação do direito ${ }^{27}$. A Teoria Pura do Direito, ao ver a função judicial como criadora do direito, põe de manifesto o sofisma subjacente à opinião, até então tradicional, que considerava o juiz como mero autômato, como "boca que pronuncia as palavras da lei". Como se verá, a teoria da interpretação jurídica desenvolvida por Kelsen guarda profunda coerência com a sua concepção de ciência, de norma jurídica e de ordenamento jurídico enquanto estrutura escalonada.

Kelsen diferencia duas espécies de interpretação jurídica - autêntica e nãoautêntica -, elevando a primeira como objeto privilegiado de sua análise. Quando o direito é aplicado por um órgão jurídico, trata-se da interpretação autêntica ${ }^{28}$. Já a interpretação não-autêntica é aquela realizada por uma pessoa privada, especialmente pela ciência jurídica. A interpretação autêntica cria direito, ao passo que a

\footnotetext{
${ }^{23}$ Cf. a crítica em DIMOULIS, Dimitri. Positivismo jurídico: introdução a uma teoria do direito e defesa do pragmatismo jurídico-político. São Paulo: Método, 2006. p. 214.

${ }^{24}$ Cf. a crítica em TROPER, Michel. Op. cit., p. 63/72.

${ }^{25}$ Zur Theorie der Interpretation. In: Internationale für Theorie des Rechts, VIII, 1934, pp. 9-17.

${ }^{26}$ É o que diz Paulo Bonavides. Segundo o jurista, tanto o artigo quanto o capítulo inserto na primeira edição da Teoria Pura do Direito tratam majoritariamente do problema das lacunas. BONAVIDES, Paulo. Curso de direito constitucional. 11. ed. São Paulo: Malheiros, 2001. p. 407/408.

${ }^{27}$ Em oposição à teoria jurídica clássica, que advogava que a atividade de realização do direito seria meramente cognitiva. Para esta corrente, que remonta à escola da Exegese, o legislador cria o direito positivo e o jurista conhece-o na sua estrutura lógico-formalmente e aplica-o também lógico-formalmente. Cf. TROPER, Michel, Op. cit., p. 63/64; BONAVIDES, Paulo. Op. cit., p. 408.

${ }^{28}$ Kelsen modifica o sentido usual da expressão "interpretação autêntica", até então utilizada para referir-se à interpretação realizada pelo próprio órgão que elaborou o ato. Ver, neste sentido: TROPER, Michel, Op. cit., p. 63.
} 
interpretação jurídico-científica (não-autêntica) não cria direito, sendo pura determinação cognoscitiva do sentido das normas jurídicas. Firme no jogo de contrastes, Kelsen estabelece que a interpretação autêntica pode assumir o caráter de lei ou tratado internacional ${ }^{29}$, como também pode assumir a forma de uma sentença ${ }^{30}$, enquanto a interpretação jurídico-científica deve ser ater a estabelecer "as possíveis significações de uma norma jurídica"31.

Kelsen elege a norma jurídica como objeto de estudo da interpretação. Não poderia ser diferente. A marca distintiva da Teoria Pura do Direito é exatamente a eleição da norma jurídica como objeto exclusivo de estudo da ciência jurídica.

Kelsen nos ensina que a interpretação consiste na determinação do sentido, do conteúdo das normas jurídicas que serão aplicadas. A interpretação é, para Kelsen, uma operação mental que acompanha necessariamente o processo de aplicação do direito no seu progredir de um escalão superior para um escalão inferior ${ }^{32}$. $\mathrm{O}$ ordenamento jurídico é concebido de forma escalonada, com o que a norma de grau superior na hierarquia normativa condiciona e determina a criação da norma jurídica de grau inferior. Neste sentido, a Constituição - norma superior - condiciona e determina o processo de produção da lei - norma inferior -, da mesma forma que a lei condiciona a produção da sentença judicial. Tem-se, assim, que a aplicação do direito é simultaneamente produção de direito, pois a norma de escalão superior é aplicada, na medida em que, de acordo com ela, se produz uma norma de escalão mais baixo ${ }^{33}$.

Apesar de a norma de escalão superior regular o ato através do qual a norma de escalão inferior é produzida, esta relação nunca é hermética. A norma de escalão superior não pode regular, em todos os sentidos e direções, o ato mediante o qual ela se aplica. É inerente ao ato de aplicação do direito uma relativa indeterminação. Esta indeterminação pode ser intencional ou não. É intencional quando o próprio órgão que estabeleceu a norma assim o quis. Kelsen apresenta o exemplo da norma penal que deixa ao juiz a opção de decidir pela aplicação de uma pena de reclusão ou multa, como sanção a um determinado delito. Já a indeterminação não-intencional deriva especialmente do caráter plurívoco do conteúdo normativo. Dada a natureza lingüística das normas jurídicas, a equivocidade é ineliminável.

A despeito da intencionalidade da indeterminação das normas jurídicas, o que se conclui é que elas são portadoras de diversas possibilidades de concretização,

\footnotetext{
${ }^{29}$ Quando cria direito de forma geral, para todos os casos iguais.

${ }^{30}$ Quando o órgão aplicador do direito cria uma norma individual ou executa uma sanção, em vista de um determinado caso concreto.

${ }^{31}$ KELSEN, Hans. Op. cit., p. 395.

${ }^{32}$ KELSEN, Hans. Op. cit., p. 387.

${ }^{33}$ LARENZ, Karl. Op. cit., p. 92.
} 
restando sempre uma margem de discricionariedade ao intérprete - autêntico chamado a estabelecer a norma inferior. Como solução ao problema, Kelsen irá se valer da figura da moldura. Segundo Kelsen, "o direito a aplicar forma, em todas as hipóteses, uma moldura dentro da qual existem várias possibilidades de aplicação, pelo que é conforme ao Direito todo ato que se mantenha dentro deste quadro ou moldura, que preencha esta moldura em qualquer sentido possível" ${ }^{34}$. Kelsen afirma sem constrangimentos que a pergunta acerca de qual dos conteúdos (sentidos) contemplados pela moldura é o correto, não pertence à teoria do direito, mas à política do direito. A eleição de qualquer um dos sentidos contemplados pela moldura é igualmente correto.

A noção kelseniana da norma jurídica como portadora de uma gama de sentidos possíveis irá colocar a Teoria Pura do Direito em franco conflito com a teoria tradicional da interpretação, que parte do pressuposto de que sempre há uma única interpretação correta, bem como de que é sua missão encontrar o método adequado para estabelecimento desta. Kelsen recusa-se a elaborar uma teoria acerca dos métodos de interpretação, pois entende como não-científica a escolha entre uma das possibilidades albergadas pela moldura normativa. Não há, pois, um critério de direito positivo capaz de realizar esta escolha. O jurista austríaco identifica na falácia de que uma norma jurídica apenas pode apresentar "uma interpretação correta", uma ficção de que se serve a jurisprudência para assegurar o ideal da segurança jurídica ${ }^{35}$.

Kelsen enfatiza a interpretação do direito como um ato que congrega "conhecimento" e "vontade". A moldura seria estabelecida por um ato de conhecimento, ao passo que um ato de vontade estabeleceria uma dentre as diversas possibilidades de aplicação. Kelsen aduz que na interpretação autêntica, aquela realizada por um órgão jurídico, "a interpretação cognoscitiva (obtida por uma operação de conhecimento) do direito a aplicar combina-se com um ato de vontade em que o órgão aplicador do direito efetua uma escolha entre as possibilidades reveladas através daquela mesma interpretação cognoscitiva" ${ }^{36}$. Na relação dialética entre conhecimento e vontade, a última sempre prevalece. Na feliz expressão de Tércio Sampaio Ferraz Júnior, trata-se de um "eu quero" em oposição a um "eu sei"

Não por outro motivo Kelsen alerta para a possibilidade de, pela via da interpretação autêntica, poder-se produzir uma norma que se situe completamente fora

\footnotetext{
${ }^{34}$ KELSEN, Hans. Op. cit., p. 390.

${ }^{35}$ KELSEN, Hans. Op. cit., p. 396.

${ }^{36}$ KELSEN, Hans. Op. cit., p. 394.

${ }^{37}$ FERRAZ JÚNIOR, Tércio Sampaio. Introdução ao estudo do direito: técnica, decisão, dominação. 2. ed. São Paulo: Atlas, 1994, p. 261.
} 
da moldura que a norma a aplicar representa. Na hipótese de uma norma oferecer, através do emprego de um termo genérico, e. g., cinco diferentes interpretações, o juiz pode escolher uma sexta significação que se coloque completamente fora da moldura normativa ${ }^{38}$. Como afirma Kelsen, uma decisão judicial "ilegal", pode, por força de seu trânsito em julgado, tornar-se definitiva, e isto não a torna "antijurídica". Com efeito, embora tal decisão possa contrariar algum preceito material ou processual previsto em norma geral, encontra respaldo jurídico em outra disposição da própria lei geral, isto é, o instituto do trânsito em julgado, que por estar assim na norma superior torna tal decisão individual conforme ao direito ${ }^{39}$. É possível, pois, a criação de direito novo para além do disposto na moldura normativa.

Como se verá a seguir, a teoria da interpretação de Kelsen é conseqüência da sua concepção de ciência. A discricionariedade atribuída ao aplicador do direito possibilitou a Kelsen admitir que questões metajurídicas - como fatores morais, éticos, políticos e sociais - influenciassem a decisão, sem que restasse comprometida a pureza metodológica de sua teoria.

\section{Críticas à teoria da interpretação de Kelsen a partir da obra de Friedrich Müller}

A teoria da interpretação de Kelsen é uma decorrência lógica de sua concepção de ciência, de norma e de ordenamento jurídico. Nas palavras já antes mencionadas de Warat, tem-se que Kelsen não se limita a expor uma epistemologia para a ciência do direito; "uma vez estabelecidas as regras de seu jogo epistemológico, decide aplicá-las para ver o que acontece" ${ }^{40}$. A crítica de Müller pretende questionar os resultados da "aplicação" das regras epistemológicas da Teoria Pura do Direito, especialmente aquelas referentes à interpretação e à aplicação do direito. Para Müller, a Teoria Pura do Direito soçobra em seu ponto decisivo, que trata da sua fecundidade para a concretização prática do direito ${ }^{41}$. A crítica de Müller centrase, pois, na absoluta separação entre ser (sein) e dever-ser (sollen), como aspecto determinante para uma teoria vazia de interpretação.

Como visto anteriormente, a Teoria Pura professa que a interpretação autêntica do direito pode ser desmembrada num ato de conhecimento e num ato de vontade. $\mathrm{O}$ ato de conhecimento põe em manifesto os sentidos possíveis da norma

\footnotetext{
${ }^{38}$ DIMOULIS, Dimitri. Op. cit., p. 211.

${ }^{39}$ KELSEN, Hans. Op. cit., pp. 295-300.

${ }^{40}$ WARAT, Luís Alberto; PÊPE, Albano Marcos Bastos. Op. cit., p. 54.

${ }^{41}$ JOANAJAN, Olivier. De Hans Kelsen a Friedrich Müller - Método jurídico sob o paradigma pós-positivista. In: MÜLLER, Friedrich. Op. cit., p. 250.
} 
jurídica aplicável, ao passo que o ato de vontade realiza uma escolha entre as alternativas dispostas no quadrante normativo. Em conclusão, a eleição de qualquer das possibilidades contempladas pela moldura normativa é correta.

Para Müller, engana-se quem pensa que, com isso, a Teoria Pura do Direito purificou a atividade jurídica. Quando da escolha das alternativas reveladas pela moldura normativa, Kelsen expressamente admite que outras "normas" podem ter incidência sobre o intérprete. E quais seriam estas "normas"? São, segundo o mestre de Viena, "normas da moral, normas da justiça, juízos de valor sociais que costumamos signar por expressões correntes como bem comum, interesse do Estado, progresso, etc." 42 Entretanto, como estas normas não fazem parte do direito positivo, são consideradas irrelevantes para a ciência do direito, que se ocupa tão somente das normas jurídicas válidas. Fiel aos seus pressupostos metodológicos, Kelsen afirma que como as normas supracitadas não fazem parte do direito positivo, "nada se pode dizer sobre a sua validade e verificabilidade"43.

Conforme explanado, quando confrontado com a questão de como se decide no interior do quadrante, Kelsen contorna a situação respondendo que se trata de questões metajurídicas, questões de política do direito. Nas palavras de Olivier Jouanjan: "Purificada destes elementos perturbadores, a teoria pura conclui-se abdicando deles: a ciência do direito está purificada, mas não a prática. No interior do quadro, a escolha da decisão não é julgável por um método (jurídico)"\$4 .

Karl Larenz, muito perspicazmente, antevê o mesmo desequilíbrio na Teoria Pura do Direito, no que se refere ao balanço entre teoria e práxis:

Assim como a jurisprudência dos interesses é deficiente como teoria, mas foi de grande utilidade prática, assim a teoria pura do Direito atinge um alto nível como teoria, mas do ponto de vista prático os seus resultados são pobres. Em último termo, porém, o fato encontra a sua razão de ser numa deficiência da própria teoria ${ }^{45}$.

Há, neste ponto, uma profunda imbricação entre a teoria da norma de Kelsen e a sua teoria da interpretação, com o que se começa a dissecar a já ventilada correlação da teoria da interpretação com os postulados epistemológicos da Teoria Pura. Para Kelsen, a norma é puro ato de vontade. A norma é uma ordem materialmente vazia, carente de inteiro fundo material, que se limita a ligar um fato condicionante a uma conseqüência, sem qualquer juízo a respeito do valor moral ou

\footnotetext{
${ }^{42}$ KELSEN, Hans. Op. cit., p. 393.

${ }^{43}$ KELSEN, Hans. Op. cit., p. 393.

${ }^{44}$ In: MÜLLER, Friedrich. Op. cit., p. 249.

${ }^{45}$ LARENZ, Karl. Op cit., p. 82.
} 
político dessa conexão ${ }^{46}$. Como ordem abstrata daquilo que deve ser, a pergunta acerca do seu conteúdo ou da sua materialidade não é de natureza jurídica ${ }^{47}$. Ora, se a norma não possui qualquer conteúdo, a pergunta pela correção material da interpretação jurídica que cria direito (norma inferior) a partir da norma superior não é sequer colocada pela Teoria Pura do Direito. Como bem sintetiza Michael Troper, "a idéia de que a norma é o significado de um ato de vontade conduz à idéia de que a própria interpretação é um ato de vontade e não um ato de conhecimento" 48 .

Müller critica a concepção da norma jurídica enquanto ordem materialmente vazia, pois tal conceito afigura-se como insuficiente para todos aqueles que partilham do Estado constitucional ${ }^{49}$. As normas constitucionais não aparecem na prática como um ato de vontade carente de inteiro fundo material.

É, pois, neste sentido, que a teoria e a metódica estruturante desenvolverão um conceito dinâmico de normatividade, decorrente de um processo estruturado metodicamente a partir das exigências do Estado de Direito. Neste processo, "os teores materiais da concretização não são ocultados, mas incluídos de forma controlável e generalizável na concretização" 50 . Isto não significa, à evidência, que a metódica estruturante propugne uma teoria da interpretação correta. Diversamente, a metódica estruturante pretende racionalizar o trabalho prático dos juristas, de forma a permitir a sua discutibilidade, revisibilidade e regularidade ${ }^{51}$. No dizer de Müller, na impossibilidade de uma racionalidade absoluta deve-se buscar a racionalidade possível para a ciência do direito.

Para além da crítica acerca da inexistência de critérios para o julgamento da decisão volitiva, coexiste em pé de igualdade a crítica acerca da inexistência de critérios para a aferição da moldura normativa - isto é, que permitam a racionaliza-

${ }^{46}$ Cf. MÜLLER, Friedrich. Op. cit., p. 16/22; REALE, Miguel. Op. cit., p. 462.

${ }^{47}$ E não poderia ser de outra forma: coerentemente com seu propósito de formular uma teoria geral do Direito que desse conta do que o Direito é em todos os tempos e lugares, Kelsen interdita para o conhecimento científico do fenômeno jurídico todo e qualquer conteúdo normativo, que é cambiante de sociedade para sociedade.

${ }^{48}$ TROPER, Michael. Op. cit., p. 64.

${ }^{49}$ Note-se que Müller situa-se dentro do paradigma (modelo jurídico-político) do Estado constitucional de direito, enquanto Kelsen se propõe a postular uma teoria universal (v. nota 46 supra).

${ }^{50}$ CHRISTENSEN, Ralph. Teoria estruturante do direito. In: MÜLLER, Friedrich. Op. cit., p. 243.

${ }^{51}$ Segundo Müller, "a teoria da norma jurídica precisa, de qualquer modo, estar especificamente a serviço da racionalidade jurídica, precisa diferenciar de modo racional as reflexões presentes na decisão, tornando-a com isso passível de controle e de discussão o máximo e o melhor possível". Cf. MÜLLER, Friedrich. Teoria estruturante do direito. Trad. Peter Naumann e Eurides Avance de Souza. São Paulo: RT, 2008. p. 161. 
ção do ato cognitivo. Apesar de perfeitamente lógica e coerente com o paradigma positivista que apresenta e enaltece, a teoria da interpretação jurídica de Kelsen não consegue responder a uma questão central: quais os métodos de interpretação capazes de traçar a moldura normativa?

Kelsen simplesmente omite quais são os métodos interpretativos capazes de auxiliar o jurista (e também o cientista) a traçar a moldura normativa, primeiro passo para a aplicação do direito. Na expressão de Müller, "os critérios do ato cognitivo, tanto no quadro da interpretação autêntica como naquele de interpretação não-autêntica são passados em silêncio; a menos que se considere o reenvio global ao procedimento lógico um ponto de apoio suficiente à verdade cientifica"52. A crítica de Müller é pertinente. Se a Teoria Pura do Direito afirma a potencialidade do jurista (e do cientista) em delimitar a moldura normativa através de um ato cognitivo, é de rigor que apresente os métodos adequados para tanto, sob pena de esvaziamento das suas proposições.

Assim como Müller, Dimitri Dimoulis censura duramente o niilismo metodológico de Kelsen. Segundo Dimoulis, a exposição de métodos interpretativos capazes de delimitar a moldura "é imprescindível, já que a afirmação da existência tanto de alternativas 'dentro' da norma como de outras que não se enquadram em seu significado perde sua relevância se não for indicado o caminho para constatar essas alternativas" $" 53$.

Em última instância, o niilismo metodológico de Kelsen termina por aproximálo do decisionismo de Schmitt ${ }^{54}$. As teorias se tocam quando se constata que o quadro normativo pode ser sumariamente rechaçado por um ato de vontade. Kelsen expressamente consigna que a interpretação autêntica é sempre válida, a despeito

\footnotetext{
${ }^{52}$ MÜLLER, Friedrich. Op. cit., p. 251; MÜLLER, Friedrich. Teoria estruturante do direito. p. 29. ${ }^{53}$ DIMOULIS, Dimitri. Op. cit., p. 211.

${ }^{54}$ Cf. MÜLLER, Friedrich. Op. cit., p. 53. Outros autores enfatizam uma aproximação da teoria da interpretação jurídica de Kelsen com o Realismo Jurídico e com a Escola do Direito Livre. Segundo Aftalión, Olano e Vilanova, que escrevem na Introducción al Derecho: "A fundamental diferença entre o voluntarismo da Escola do Direito Livre e o de Kelsen consiste em que o daquela é um voluntarismo amorfo ou informe (Cosio), porquanto deixa tudo entregue livremente à vontade do juiz. Em compensação, o voluntarismo kelseniano se acha estruturado de fora (voluntarismo estruturado), no sentido de que o juiz não está livre de ataduras e que o seu ato de vontade deve discorrer dentro dos marcos conceituais - tipos figuras, 'standards' - enunciados pelas normas gerais, segundo já explicamos ao tratar da compreensão no âmbito do Direito (AFTALIÓN, E. R.; OLANO, F.G.; VILANOVA J., Op. cit., p. 443)”. In: BONAVIDES, Paulo. Op. cit., p. 411. De outro lado, propugnando uma identificação entre o positivismo de Kelsen e o realismo americano, tem-se a lição de Dimoulis: "No outro extremo encontramos a postura de Kelsen, de Hart e de muitos outros autores que silenciam sobre as finalidades e os métodos da interpretação, convergindo com o realismo jurídico". DIMOULIS, Dimitri. Op. cit., p. 218.
} 
de sua conformidade com a moldura normativa. O órgão aplicador do direito que possui competência para decidir em última instância pode produzir uma norma que se situe completamente fora da moldura que a norma a aplicar representa ${ }^{55}$. Em ambas as teorias subsiste a possibilidade de dissolução da normatividade por um mero ato de vontade. Nas palavras de Müller, "em ambos os casos, teores materiais são superados de forma voluntarista" ${ }^{56}$.

A teoria de Müller parte da recusa da construção teórica de Kelsen. Müller refuta a relação entre norma e realidade tal como ela se processa na Teoria Pura do Direito. A Teoria Estruturante do Direito se propõe a repensar a relação normarealidade, fato-norma, através de uma nova teoria da norma jurídica, que se pergunta pela estrutura de sua normatividade tal como se apresenta na aplicação prática do direito ${ }^{57}$. Müller transmuda a pergunta por "norma e fato" pela pergunta pela normatividade e estrutura da norma ${ }^{58}$.

A originalidade da teoria da norma de Müller reside na estrutura normativa por ele proposta. Para Müller, não é apenas a injunção de dever-ser que contribui para a decisão do caso, mas também, no que toca a uma série de tipos de normas, igualmente a estrutura substancial do âmbito de regulação, da parcela da realidade social relacionada com a norma ${ }^{59}$. Enquanto a Teoria Pura do Direito assenta-se no dualismo incomunicável entre norma e realidade empírica, ser e dever-ser ${ }^{60}$, a Teoria Estruturante do Direito congrega estes dois elementos dentro da teoria da norma. Reside, pois, no entrecruzamento ordenado entre norma e realidade, uma diferença substancial entre a teoria de Müller e a teoria de Kelsen.

Outras críticas de Müller a Kelsen poderiam ser aqui arroladas, dentre elas a de como sua concepção de ciência, fundada na separação entre sujeito e objeto e convicta da possibilidade de uma investigação isenta de valores, evidenciou-se uma simplificação insustentáve $1^{61}$. Entretanto, passe-se, por ora, a uma breve exposição da Teoria Estruturante do Direito, de forma a evidenciar algumas das suas diferenças em relação à Teoria Pura. De fato, a teoria de Müller começa onde se detém a

\footnotetext{
${ }^{55}$ KELSEN, Hans. Op. cit., p. 394.

${ }^{56}$ MÜLLER, Friedrich. Op. cit., p. 55.

${ }^{57}$ MÜLLER, Friedrich. Op. cit., p. 17.

${ }^{58}$ MÜLLER, Friedrich. Teoria estruturante do direito. p. 07.

${ }^{59}$ MÜLLER, Friedrich apud LARENZ. p. 155.

${ }^{60}$ Essa separação não é absoluta, dado que, para Kelsen, entre vigência e eficácia pode existir uma certa conexão [...] Um mínimo de eficácia [da norma] é a condição de sua vigência” (Op. cit, p. 12). E mais: ao nível de ordenamento só se pode inferir a existência de uma grundnorm a fundamentar toda a validade do ordenamento se esse ordenamento for, em seu conjunto, eficaz (p. 237). Sobre a relação validade/eficácia na Teoria Pura do Direito, v. CADEMARTORI, S. Estado de Direito e legitimidade: uma abordagem garantista. Campinas: Millennium, 2007.
}

${ }^{61}$ MÜLLER, Friedrich. Teoria estruturante do direito. pp. 9-15. 
obra de Kelsen. Não é por outro motivo que Paulo Bonavides saúda a Teoria Estruturante como "o livro mais importante de direito que se imprimiu na Alemanha" desde o "lançamento da Teoria Pura do Direito de Hans Kelsen, há 50 anos, e da Tópica e Jurisprudência de Viehweg, há três décadas [...]"62.

O decisivo para a compreensão da teoria da norma de Müller é a não-identidade entre norma e texto normativo. O teor literal da norma, juntamente com todos os recursos interpretativos auxiliares, expressa tão-somente o que Müller denomina de programa da norma ${ }^{63}$ (resultado do trabalho de interpretação). Pertence igualmente à norma, em grau hierárquico igual, o chamado âmbito da norma ${ }^{64}$ (resultado do trabalho de análise do segmento da realidade referida) ${ }^{65}$. Assim, a norma será formada pelo programa da norma e pelo âmbito da norma, só podendo ser compreendida pela recíproca articulação destas dimensões.

A “norma”, como diz Müller, é muito mais ampla do que o "texto normativo". A norma jurídica não está pronta nem substancialmente acabada, não está no texto positivo. A norma deverá ser construída através do processo de concretização. A concretização de uma norma transcende à mera interpretação do texto ${ }^{66}$, e será disciplinada por métodos jurídicos, com o que se articulam teoria da norma e metodologia jurídica ${ }^{67}$. E quais seriam estes métodos?

Müller estrutura o processo de concretização a partir de dois grupos de elementos, quais sejam: (i) elementos metodológicos referidos ao texto da norma ${ }^{68} \mathrm{e}$

\footnotetext{
${ }^{62}$ BONAVIDES, Paulo. Teoria Estrutural do Direito de Friedrich Müller. In: MÜLLER, Friedrich. Op. cit., p. 233.

${ }^{63}$ MÜLLER, Friedrich. Op. cit., p. 224. "O programa da norma é formado pelo texto da norma, trabalhado pelos dados da linguagem, visando à sua aplicação ao caso”. Cf. B

ORNHOLDT, Rodrigo Meyer. Métodos para a resolução de conflitos entre direitos fundamentais. São Paulo: RT, 2005. p. 40.

${ }^{64} \mathrm{O}$ âmbito normativo será aquela parcela da realidade situada em conformidade com as prescrições do programa da norma. O âmbito normativo "é o recorte da realidade social na sua estrutura básica, que o programa da norma "escolheu" para si ou em parte criou para si como seu âmbito de regulamentação [...] podendo ter sido gerado (prescrições referentes a prazos, datas, prescrições de forma, regras institucionais e processuais, etc.) ou não pelo direito". Cf. MÜLLER, Friedrich. Métodos de trabalho do direito constitucional. 2. ed. Trad. Peter Naumann. São Paulo: Max Limonad, 2000. p. 57; BORNHOLDT, Rodrigo Meyer. Op. cit., p. 46.

${ }^{65}$ JOAUJAN, Olivier. In: MÜLLER, Friedrich. Op. cit., p. 259.

${ }^{66} \mathrm{~A}$ interpretação, na teoria de Müller, tem sentido mais restrito, pois diz respeito às possibilidades de tratamento do texto, isto é, da interpretação de textos de normas.

${ }^{67}$ JOAUJAN, Olivier. In: MÜLLER, Friedrich. Op. cit., p. 257.

${ }^{68}$ A interpretação do texto da norma se realiza segundo os cânones desenvolvidos por Savigny: interpretação gramatical, genética, histórica e teleológica, bem como mediante os modernos princípios de interpretação da constituição - princípio da interpretação conforme à constituição, da unidade e da concordância prática.
} 
(ii) elementos metodológicos de análise do âmbito da norma. Outrossim, ingressam no processo de concretização os elementos dogmáticos, os elementos teóricos, os elementos de técnica de solução, os elementos de política do direito e política constitucional $^{69}$.

Em caso de conflito, os argumentos diretamente referidos às normas prevalecem sobre aqueles mais distantes. No dizer de Ralph Christensen: "Isso significa, por exemplo, que no caso de resultados contraditórios dos diferentes elementos de concretização, um elemento metodológico no sentido mais estrito referido ao texto da norma derrota um elemento meramente juspolítico ou um elemento dogmático não diretamente referido à norma" ${ }^{70}$. Vê-se, aqui, mais uma diferença entre a teoria de Müller e a de Kelsen. A metódica estruturante fornece elementos objetivos para a atividade prática de aplicação do direito, o que Kelsen se recusa a fazer, por considerar tal empreendimento incompatível com a ciência do direito.

Nomeadamente no que se refere à metódica de Müller, convém novamente alertar que antes de um critério de obtenção de verdade ou meramente descritivo (de uma prática autonomamente constituída, atuando a posteriori), o que ela efetivamente deseja é criar um processo de decisão que permita a sua discutibilidade, revisibilidade e regularidade.

Müller reivindica um processo normativo vinculado ao caso concreto, em que a formação/estruturação da norma jurídica obedece a uma série de critérios. A metódica estruturante parte inicialmente do texto normativo para a elaboração do programa da norma (Normprogram), que, por sua vez, condicionará a elaboração do âmbito da norma (Normbreich). Da articulação do programa da norma e do âmbito da norma surgirá a norma jurídica (Rechtsnorm) que, posteriormente, se concretizará na norma de decisão (Entscheidungsnorm).

\section{Considerações finais}

O presente artigo procurou enfatizar a relação entre a epistemologia proposta na Teoria Pura do Direito e a teoria da interpretação jurídica de Kelsen. Procurouse analisar em que medida a concepção de norma e de ordenamento jurídico influencia a teoria da interpretação de Kelsen.

A teoria da interpretação jurídica de Kelsen está estruturada em torno dos seguintes pressupostos: (i) a interpretação consiste em estabelecer o conteúdo das

\footnotetext{
${ }^{69}$ CHRISTENSEN, Ralph. Op. cit. In: MÜLLER, Friedrich. Op. cit., p. 243.

${ }^{70}$ CHRISTENSEN, Ralph. Op. cit. In: MÜLLER, Friedrich. Op. cit., p. 243.
} 
normas jurídicas que hão de ser aplicadas; (ii) deve-se diferenciar a interpretação autêntica (criadora de direito) da interpretação não-autêntica (meramente cognoscitiva); (iii) a norma a ser aplicada deixa em aberto, intencionalmente ou não, diversas possibilidades interpretativas, em virtude da sua natureza lingüística; e (iv) a norma a aplicar forma uma moldura, dentro da qual existem várias possibilidades de aplicação, pelo que é conforme ao Direito todo ato que preencha esta moldura em qualquer sentido possível.

Ainda no que tange à teoria da interpretação, viu-se que Kelsen: (i) recusa-se a elaborar uma teoria acerca dos métodos de interpretação, silenciando sobre os métodos capazes de regular o ato cognitivo; (ii) considera a escolha entre uma das possibilidades albergadas pela moldura normativa como não-científica; e (iii) adverte para a possibilidade de, pela via da interpretação autêntica, poder-se produzir uma norma que se situe completamente fora da moldura que a norma a aplicar representa.

Quanto à crítica de Müller à teoria de Kelsen, merecem destaque os seguintes aspectos: (i) dada a concepção de norma como ordem materialmente vazia, a pergunta pela correção material da interpretação jurídica que origina a norma inferior a partir da norma superior não é sequer colocada pela Teoria Pura do Direito; (ii) a teoria da interpretação de Kelsen esvazia-se quando o jurista austríaco silencia sobre os elementos metodológicos capazes de traçar a moldura; e (iii) o niilismo metodológico de Kelsen termina por aproximá-lo do decisionismo de Schmitt.

De qualquer sorte, as reflexões teóricas de Kelsen têm servido de base para enriquecer as fecundas críticas que a partir do modelo constitucional lhe são dirigidas por autores que, como Müller, enfatizam a (problemática) inserção de conteúdos normativos como elemento indissociável da definição do Direito no novo paradigma.

\section{Referências}

BONAVIDES, Paulo. Curso de direito constitucional. 11. ed. São Paulo: Malheiros, 2001.

. Teoria Estrutural do Direito de Friedrich Müller. In: MÜLLER,

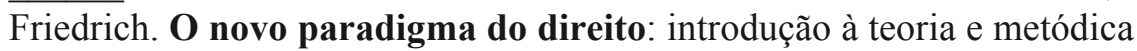
estruturantes. Trad. Peter Naumann. São Paulo: RT, 2008.

BORNHOLDT, Rodrigo Meyer. Métodos para a resolução de conflitos entre direitos fundamentais. São Paulo: RT, 2005.

CADEMARTORI, Sergio. Estado de Direito e legitimidade: uma abordagem garantista. Campinas: Millennium, 2007. 
CASTANHEIRA NEVES, Antônio. Método jurídico. Digesta: escritos acerca do direito, do pensamento jurídico, de sua metodologia e outros. Coimbra: Coimbra, 1995. vol. II.

CHRISTENSEN, Ralph. Teoria estruturante do direito. In: MÜLLER, Friedrich. O novo paradigma do direito: introdução à teoria e metódica estruturantes. Trad. Peter Naumann. São Paulo: RT, 2008.

DIMOULIS, Dimitri. O positivismo jurídico: introdução a uma teoria do direito e defesa do pragmatismo jurídico-político. São Paulo: Método, 2006.

FERRAZ JÚNIOR, Tércio Sampaio. Introdução ao estudo do direito: técnica, decisão, dominação. 2. ed. São Paulo: Atlas, 1994.

JOUANJAN, Olivier. De Hans Kelsen a Friedrich Müller - Método jurídico sob o paradigma pós-positivista. In: MÜLLER, Friedrich. O novo paradigma do direito: introdução à teoria e metódica estruturantes. Trad. Peter Naumann. São Paulo: RT, 2008.

KAUFMANN, Arthur. Filosofia do direito. Trad. António Ulisses Cortês. Lisboa: Calouste Gulbenkian, 2004.

KELSEN, Hans. Teoria pura do direito. Trad. João Baptista Machado. 7. ed. São Paulo: Martins Fontes, 2006.

LARENZ, Karl. Metodologia da ciência do direito. Trad. José Lamego. 2. ed. Lisboa: Calouste Gulbenkian, 1983.

MÜLLER, Friedrich. Métodos de trabalho do direito constitucional. 2. ed. Trad. Peter Naumann. São Paulo: Max Limonad, 2000.

. O novo paradigma do direito: introdução à teoria e metódica estruturantes. Trad. Peter Naumann. São Paulo: RT, 2008.

. Teoria estruturante do direito. Trad. Peter Naumann e Eurides Avance de Souza. São Paulo: RT, 2008.

REALE, Miguel. Filosofia do direito. 11. ed. São Paulo: Saraiva, 1986.

TROPER, Michel. Por una teoría del Estado. Trad. Maria Venegas Grau. Madrid: Dykinson, 2001.

WARAT, Luís Alberto; PÊPE, Albano Marcos Bastos. Filosofia do direito: uma introdução crítica. São Paulo: Moderna, 1996. 